\title{
DIFFERENT TYPES OF POWER TRANSFORMING MACHINES WITH ROTATING PISTONS
}

\author{
Piotr Drogosz \\ University of Warmia and Mazury \\ Technical Sciences Faculty, Department of Mechatronics \\ Słoneczna Street 16A, 10-710 Olsztyn, Poland \\ tel.: +48 89 5245101, fax: +48 895245150 \\ e-mail: piotr.drogosz@uwm.edu.pl
}

\begin{abstract}
This article describes the basic principles for determining the geometry of different types of power transforming machines with rotating pistons. Those machines can be used as internal combustion engines, pumps, hydraulic engines, compressors, flowmeters, feeders etc. An attempt is made to clarify whether it is possible to construct machines with rotating pistons for more general use. Differences in description in many sources lead to problems when it comes to comparison of information coming from these sources. An analysis of the data indicates that reorganizing the basic mathematical issues would be useful. In this article we choose and describe one most convenient name and form of mathematical equation. Many other applications of the chosen form of mathematical equation ascertain proper and convenient use. This is the first time that the chosen form of mathematical equation is proposed to be used to find constructions of different types of power transforming machines with rotating pistons. The main advantage of this form of mathematical equation is the application of two main parameters: curve size parameter and dimensionless curve parameter. These two parameters decided about the convenience in changing volume of internal combustion engines and comparisons of performance characteristic of different types of power transforming machines with rotating pistons. In this paper some convenient values of parameters dimensionless curve parameter are put and discussed.
\end{abstract}

Keywords: power transforming machines, rotating pistons, internal combustion engines, pumps, hydraulic engines

\section{Introduction}

In [2] a new form of mathematical equation is proposed to be used in accordance with construction of Wankel engines. The main advantage of this form of mathematical equation is the application of two main parameters: curve size parameter and dimensionless curve parameter. These two parameters decided about the convenience in changing volume of internal combustion engines and comparisons of performance characteristic of different types of power transforming machines with rotating pistons. However in these mathematical equations it is possible to change value of number of curve cycles of the preliminary curve, to which, on the basis of conditions for ideal work, the remaining constructional shapes should be found. These possibilities were checked and the results described in the remaining part of the paper.

\section{Conditions of ideal work}

First of all, the correct form of equation of the preliminary curve should be used. To fulfil all mechanical conditions of Wankel engines the following formula of the preliminary curve equation should to be applied:

$$
\left\{\begin{array}{l}
x=a \cdot \cos \varphi+a \cdot p \cdot \cos [(k+1) \cdot \varphi], \\
y=a \cdot \sin \varphi+a \cdot p \cdot \sin [(k+1) \cdot \varphi],
\end{array}\right.
$$

where:

$a$ - curve size parameter in $\mathrm{mm}$, 
$k-$ number of curve cycles (lobes),

$p-$ dimensionless curve parameter,

$\varphi-$ independent variable ( $\mathrm{rad})$,

$e=a \cdot p-$ distance of the centre of rotation of the piston from the centre of rotation of the engine shaft.

In equation (1) special care should be taken to note correct signs ' + ' and ' - '. This problem was partly discussed in [3]. Generally, when concrete numeric values are put for all given parameters the problem is clear. Some changes of sings ' + ' and '-' only rotate the geometry of preliminary curve. However some combinations of sings ' + ' and ' - ' depend on all mechanical conditions of mechanical structure of a mechanism. Mechanical structure of the mechanism can be described as a correct mathematical formula of trochoid. Other changes of other sings ' + ' and '-' depend on agreement of number of curve cycles (lobes) which should be used with chosen mechanical structure of the mechanism.

In order to fulfil the conditions of ideal work of different types of power transforming machines with rotating pistons first the proper value of the number of curve cycles (parameter $k$ ) should be chosen. In this paper the number of parameter $k$ was changed from 1 to 6 . Next, the value of the curve size parameter, $a$, should be chosen. The $a$ parameter is independent and in this paper was modified to obtain the same oversize of different constructions. The selection of correct value of dimensionless curve parameter $p$ is more difficult. The main mechanical limitation of numeric value of parameter $p$ depends on the appearance of singular points of an analytic function of preliminary curve. This limit can be described as the appearance of spinodal point or a small loop on the curve. From mathematical point of view the better criterion is the appearance of a small loop. The limitations of numeric value of dimensionless curve parameter $p$ ware described in Tab. 1. Maximum numeric values of small loop criterion can be seen in second column. Independent of small loop criterion, in order to fulfil all mechanical conditions of mechanical structure of mechanism the maximum value of parameter $p$ should be smaller. In the third column of Tab. 1 we can see the values were used to draw figures showed in Fig. 1 and 2. These values of proper contact criterion in this paper are the half of small loop criterion. However in many applications other mechanical conditions of mechanical structure and technology of mechanism constrain farther reduction of values of parameter $p$. For example, in Wankel engine produced by Mazda and showed in Fig. 3 the values of parameter $p=1 / 7=0.142857143$ for $k=2$.

Tab. 1. Limitation of numeric value of dimensionless curve parameter

\begin{tabular}{|c|c|c|}
\hline$k$ & small loop & proper contact \\
\hline 1 & 0.50005 & 0.250025 \\
\hline 2 & 0.3334 & 0.1667 \\
\hline 3 & 0.2501 & 0.12505 \\
\hline 4 & 0.2002 & 0.1001 \\
\hline 5 & 0.1668 & 0.0834 \\
\hline 6 & 0.1432 & 0.0716 \\
\hline
\end{tabular}

In Fig. 1 and 2 we can see different types of power transforming machines with rotating pistons with $(k+1)$ and $(k-1)$ lobes. Different types of construction can be obtained with the same preliminary curve on the basis of conditions for ideal work. The choice of rotating piston with $(k+1)$ and $(k-1)$ lobes depends on piston rotating mechanism and other criteria of whole work of selected power transforming machine. In Fig. 3-6 we can see many different similar constructions were built and used, though these examples were built without universal theory. 

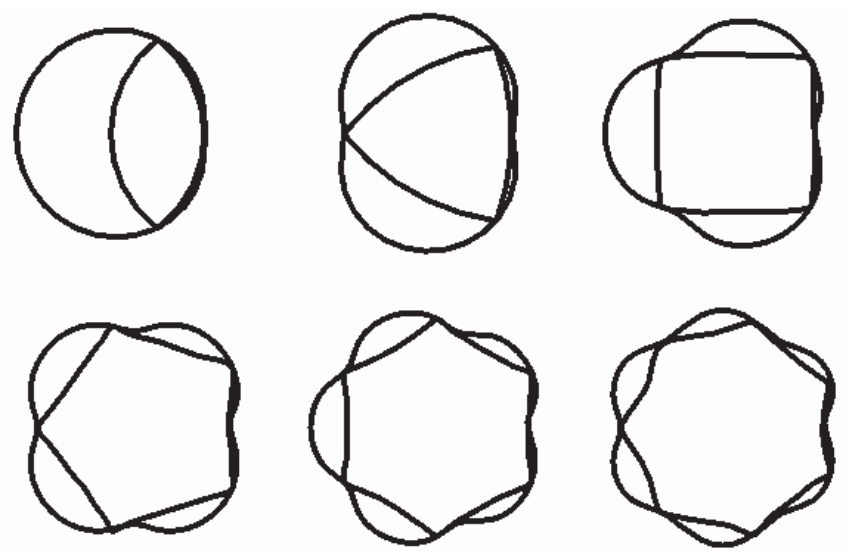

Fig. 1. Different types of power transforming machines with rotating pistons with $(k+1)$ lobes
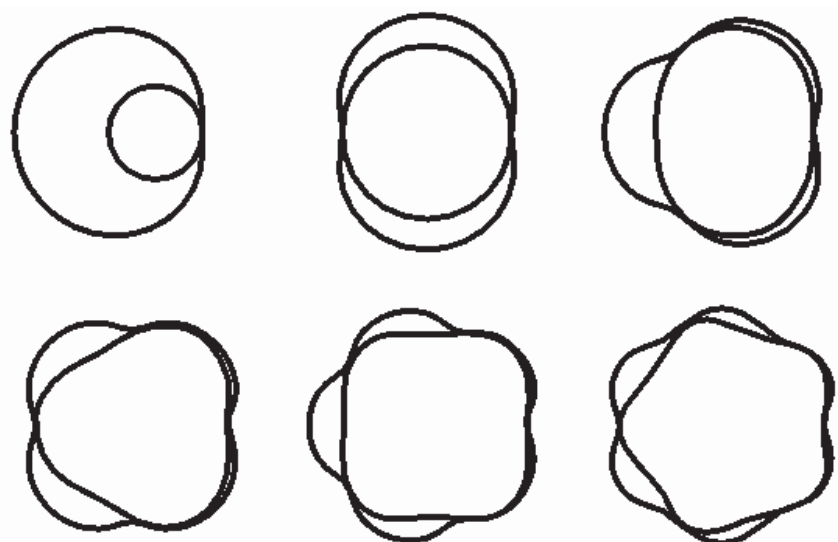

Fig. 2. Different types of power transforming machines with rotating pistons with $(k-1)$ lobes

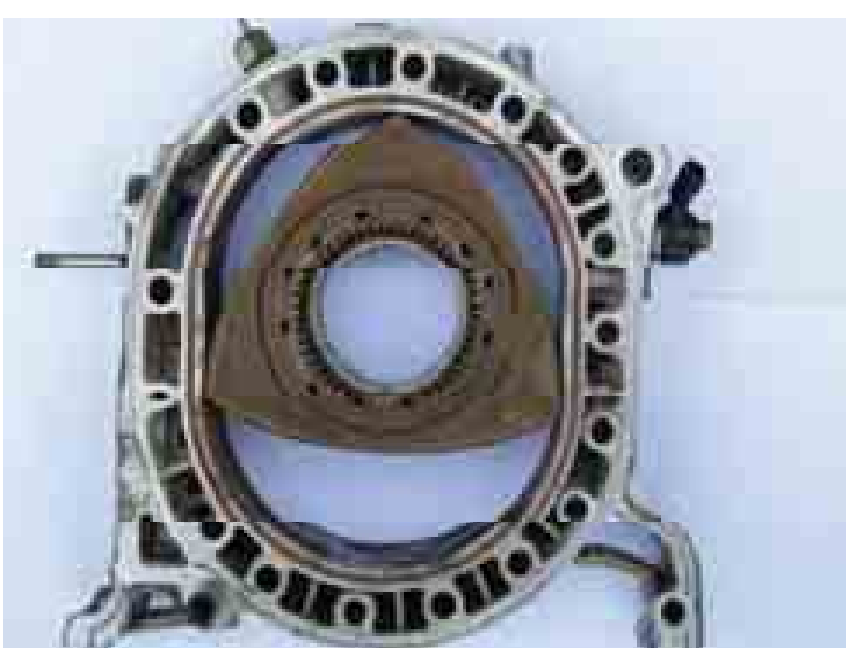

Fig. 3. Photo of rotary piston and motionless cylinder of Wankel combustion engine [2]

\section{Results}

1) It is possible to use one general theory to build different types of power transforming machines with rotating pistons.

2) An analytic continuity function of preliminary curve enables a comprehensive research of practical possibility of building different types of power transforming machines with rotating pistons.

3) From the same preliminary curve but two different piston rotating mechanism, it is possible to obtain two different types of power transforming machines with rotating pistons. 


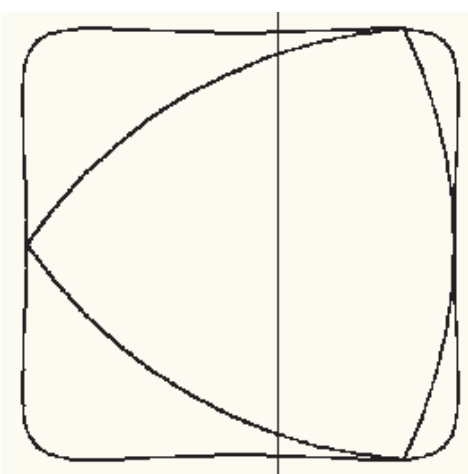

Fig. 4. Geometry of rotary piston and motionless cylinder taken from Polish patents 48191 and 48198 [1]

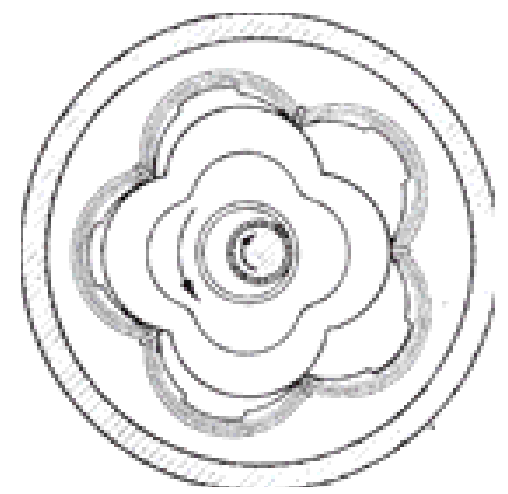

Fig. 5. Geometry of rotary piston and motionless cylinder of RENAULT-AMERICAN MOTORS [1]

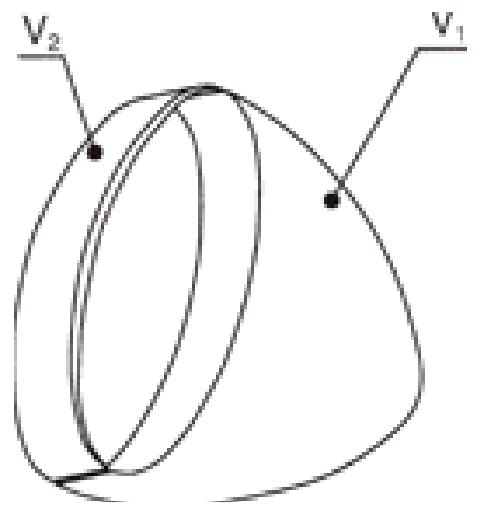

Fig. 6. Geometry of rotary piston and motionless cylinder of new pomp [4]

\section{References}

[1] Bernhardt, M., Silniki spalinowe o tłokach obrotowych, Wydawnictwa Komunikacji i Łączności, Warszawa 1964.

[2] Drogosz, P., Geometry of the Wankel Rotary Engine, Journal of KONES Powertrain and Transport, Vol. 17, No. 3, 2010.

[3] Drogosz, P., Trajectory of the Apex Seals of the Wankel Rotary Engine, Journal of KONES Powertrain and Transport, Vol. 18, No. 2, 2011.

[4] Gajowniczek, K., Prototypowa pompa wyporowa [in Polish], Hydraulika i Pneumatyka 3/2009. 